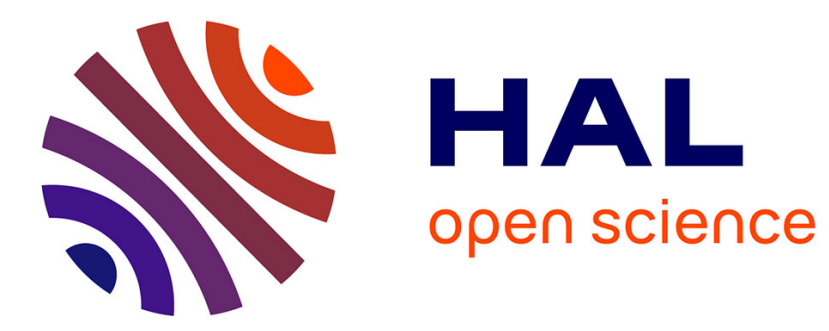

\title{
On the Enantioselective Phosphoric-Acid-Catalyzed Hantzsch Synthesis of Polyhydroquinolines
}

Ophélie Quinonero, Clément Lemaitre, Marion Jean, Nicolas Vanthuyne, Christian Roussel, Damien Bonne, Thierry Constantieux, Cyril Bressy, Xavier Bugaut, Jean Rodriguez

\section{To cite this version:}

Ophélie Quinonero, Clément Lemaitre, Marion Jean, Nicolas Vanthuyne, Christian Roussel, et al.. On the Enantioselective Phosphoric-Acid-Catalyzed Hantzsch Synthesis of Polyhydroquinolines. Organic Letters, 2021, 23 (9), pp.3394-3398. 10.1021/acs.orglett.1c00866 . hal-03285117

\section{HAL Id: hal-03285117 https://hal.science/hal-03285117}

Submitted on 13 Jul 2021

HAL is a multi-disciplinary open access archive for the deposit and dissemination of scientific research documents, whether they are published or not. The documents may come from teaching and research institutions in France or abroad, or from public or private research centers.
L'archive ouverte pluridisciplinaire $\mathbf{H A L}$, est destinée au dépôt et à la diffusion de documents scientifiques de niveau recherche, publiés ou non, émanant des établissements d'enseignement et de recherche français ou étrangers, des laboratoires publics ou privés. 


\title{
On the Enantioselective Phosphoric-Acid-Catalyzed Hantzsch Synthesis of Polyhydroquinolines
}

\author{
Ophélie Quinonero, Clément Lemaitre, Marion Jean, Nicolas Vanthuyne, Christian Roussel, \\ Damien Bonne, Thierry Constantieux, Cyril Bressy,* Xavier Bugaut,* and Jean Rodriguez*
}

ABSTRACT: A reinvestigation of a chiral phosphoric-acidcatalyzed four-component Hantzsch enantioselective synthesis of polyhydroquinolines reported in 2009 is presented. In our hands, when the reaction was performed with fidelity to the original report using a chiral enantiopure phosphoric acid catalyst, no enantioselectivity was observed. Unlike in the original report, enantioselectivity results are backed by baseline separation of the

enantiomers by HPLC analyses on chiral stationary phase with UV and chiroptical detection.
$\mathrm{R}$ ecently, our group ${ }^{1}$ has developed an atroposelective version of the Hantzsch pyridine synthesis (Scheme 1 ). ${ }^{2}$ Our strategy was to achieve the enantioselective organocatalytic preparation of suitably substituted 4-aryl-1,4-dihydropyridines (DHPs) $2^{3}$ and then oxidize them into the corresponding 4arylpyridines 3 , with a central-to-axial conversion of chirality. ${ }^{4}$ The first challenge was to prepare enantioenriched 4-aryl-1,4DHPs that bear at least three substituents around the stereogenic axis ${ }^{5}$ providing the required steric hindrance to ensure high enough barriers to rotation in the final products. Our studies began by a survey of the literature methods to synthesize enantioenriched 4-aryl-1,4-DHPs to define which ones tolerate additional steric hindrance. Generally, these transformations rely on a 1,4-addition to a Michael acceptor followed by an annulation process. Singh's stepwise synthesis combining 2-enoylpyridines and cyclic 1,3-diketones in the

Scheme 1. Atroposelective Hantzsch Pyridine Synthesis

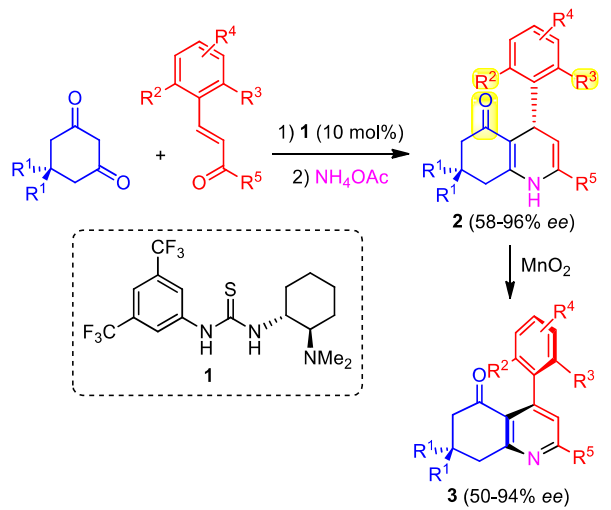

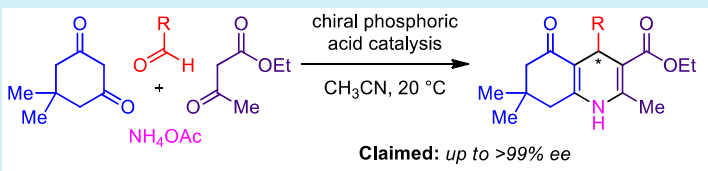

Attempts to reproduce the results: no enantiose/ectivity
Scheme 2. Enantioselective Organocatalytic Hantzsch Synthesis of Polyhydroquinolines: Literature Report and Our Early Results

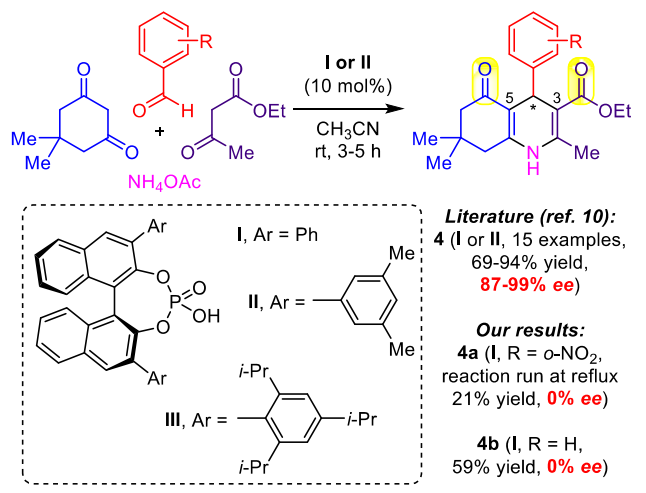

presence of Takemoto catalyst $\mathbf{1}$ allowed the preparation of a series of targeted compounds 2. ${ }^{6}$ However, the other methodologies that were evaluated, including those of Renaud, ${ }^{7}$ Gong, ${ }^{8}$ and Rueping, ${ }^{9}$ furnished no expected product. Either the substrates remained unreacted, even in more forcing reaction conditions than in the original reports, or competing pathways including 1,2-addition became predominant over the desired 1,4-addition. 

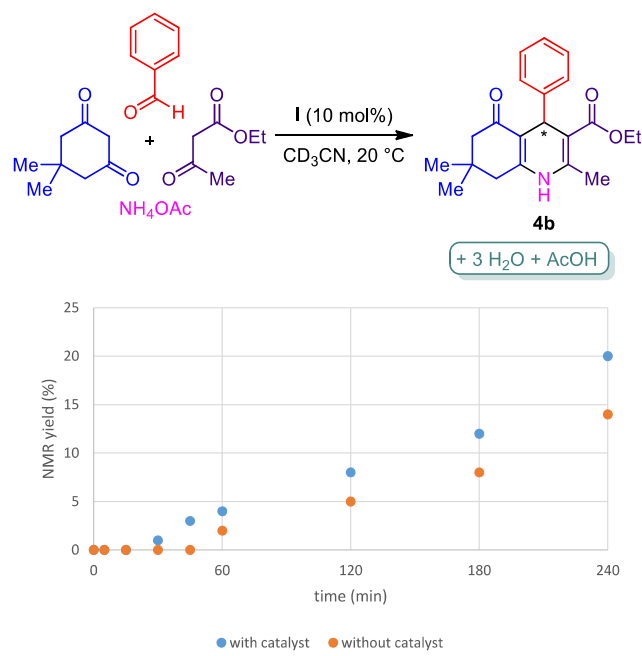

Figure 1. Conversion over time in the presence or absence of catalyst.

Table 1. Influence of $\mathrm{NH}_{4} \mathrm{OAc}$ and the Catalyst ${ }^{a}$

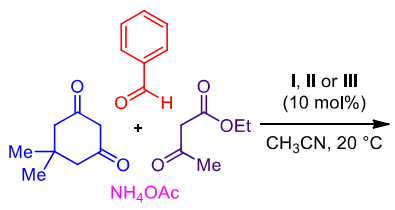

entry

1

2

3

5

catalyst $\mathrm{I}$ and no $\mathrm{NH}_{4} \mathrm{OAc}$

catalyst II

catalyst III

catalyst III, $0{ }^{\circ} \mathrm{C}$

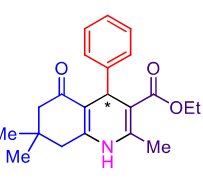

4b catalyst $\mathrm{I}, \mathrm{AcOH}$ instead of $\mathrm{NH}_{4} \mathrm{OAc}$

catalyst III, $-20^{\circ} \mathrm{C}$ results

no conversion

no conversion

$38 \%, 0 \%$ ee

$47 \%, 0 \%$ ee

$77 \%, 0 \%$ ee

no conversion

${ }^{a}$ Yield of analytically pure product after purification by flash chromatography and ee determined by HPLC on chiral stationary phase after identification of the enantiomers by baseline separation on the racemic mixture.

Alternatively, one of the most appealing methods in the literature was the report by Evans and Gestwicki consisting of the four-component reaction between ethyl acetoacetate, dimedone, aldehydes, and ammonium acetate in the presence of enantiopure BINOL-derived phosphoric acids I and II (Scheme 2) ${ }^{10}$ Indeed, the expected polyhydroquinolines 4 were assembled in a single synthetic operation from commercially available starting materials in impressive yields and enantioselectivities for such a complex transformation. Even more interesting for us, the 4-aryl-1,4-DHP ring of 4 was flanked by two different carbonyl substituents on positions 3 and 5, opening a possibility to attain sufficient steric hindrance even using aromatic aldehydes substituted only at one of the two ortho positions. $o$-Nitrobenzaldehyde was selected to start investigating this transformation in the presence of enantiopure catalyst $\mathbf{I}$. The reaction mixture had to be refluxed to observe the formation of product $4 a$. It was isolated in $21 \%$ yield, but its analysis by HPLC on chiral stationary phase (Chiralpak IC, Hept/EtOH 70:30, $1 \mathrm{~mL} \mathrm{~min}^{-1}$, UV and circular dichroism CD detectors, $\sim 3 \mathrm{~min}$ interval between the signals of the two

(a) Chromatogram from the original report (ref. 10a)

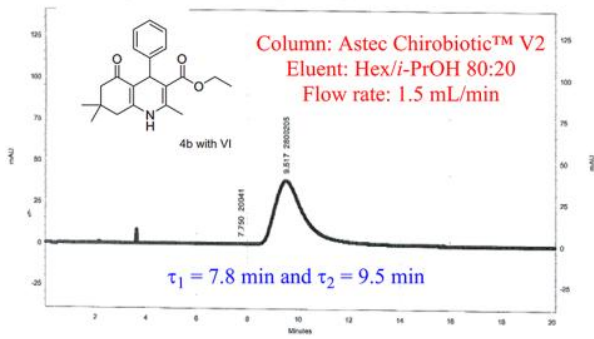

(b) Attempt to reproduce the original separation conditions

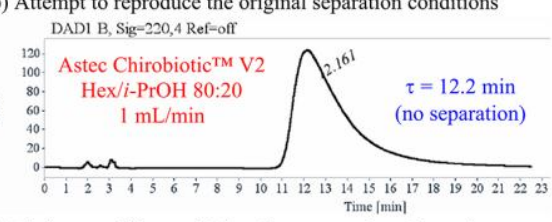

(c) Elution conditions with baseline separation of enantiomers
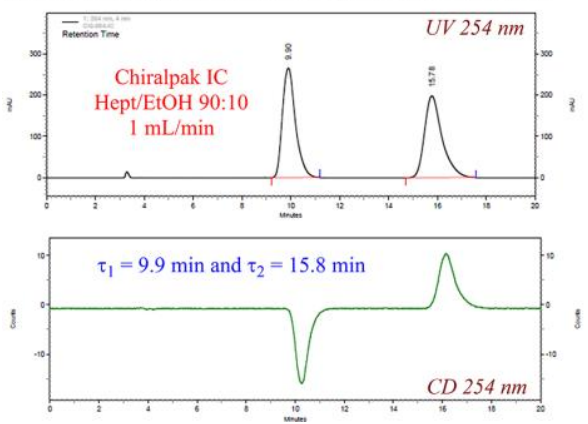

Figure 2. Selected HPLC data for compound $\mathbf{4 b}$.

enantiomers ${ }^{12}$ ) revealed no enantioselectivity. Suspecting that the nitro substituent and/or the increase in the reaction temperature might have a deleterious influence on the enantioselection process, we repeated the preparation of product $4 \mathbf{b}$, which was present in the original report. ${ }^{10 a}$ Surprisingly, this second product was also isolated as a racemate. Puzzled by these results, we conducted an in-depth evaluation of our operating conditions including the repurification of catalyst $\mathbf{I}^{11}$ and all starting materials, the use of a brand-new batch of ammonium acetate, and the purification of the product by several techniques (recrystallization or flash chromatography), without any influence on the stereochemical outcome of the reaction. ${ }^{12}$ Moreover, home-prepared catalyst $\mathbf{I}$ evaluation in another protocol described in the literature attested to its integrity. ${ }^{12,13}$

At this point of the study, a close analysis of the original publication raised the following questions: ${ }^{10 a}$

(i) The reaction is said not to proceed in the absence of the catalyst, but product $4 \mathrm{~b}$ was obtained with good yields $(75-90 \%)$ in comparable reaction times $(3-5 \mathrm{~h})$ with catalysts as different as $\mathrm{Yb}(\mathrm{OTf})_{3}$, a proline derivative, chiral diphosphines, and chiral phosphoric acids. It appeared unclear how such diversified chemical entities that are likely to proceed by different modes of activation could result in very similar results. Moreover, all chiral catalysts but the phosphoric acids resulted in negligible enantioinduction. 
Table 2. Test of Various Aldehydes ${ }^{a}$

\begin{tabular}{|c|c|c|c|c|c|c|c|}
\hline Entry & $\mathrm{R}$ & Catalyst & Product number & Lit. yield $(\%)^{[10 a, 17]}$ & Lit. ee $(\%)^{[10 a, 17]}$ & Yield $(\%)^{[b]}$ & $e e(\%)^{[c]}$ \\
\hline 1 & 4- $\left[\left(\mathrm{CH}_{3}\right)_{2} \mathrm{~N}\right] \mathrm{C}_{6} \mathrm{H}_{4}$ & II & $4 c$ & $75-78$ & 93 & 92 & $\mathbf{0}$ \\
\hline 2 & $2-\mathrm{CF}_{3} \mathrm{C}_{6} \mathrm{H}_{4}$ & $\mathbf{I}$ & $4 d$ & $79-85$ & $>99$ & 38 & $\mathbf{0}$ \\
\hline 3 & $\mathrm{PhCH}_{2} \mathrm{CH}_{2}$ & II & $4 e$ & $92-94$ & 94 & 28 & $\mathbf{0}$ \\
\hline 4 & & III & $4 f$ & 25.92 & $>90$ & 35 & 7 \\
\hline
\end{tabular}

${ }^{a}$ Reaction conditions: mixture of dimedone (1.5 equiv), ethyl acetoacetate (1.0 equiv), catalyst ( 0.1 equiv), aldehyde (1.0 equiv), and $\mathrm{NH}_{4} \mathrm{OAc}$ (1.0 equiv) in $\mathrm{CH}_{3} \mathrm{CN}$ stirred at room temperature for the appropriate time. ${ }^{b}$ Yield of analytically pure product after purification by flash chromatography. ${ }^{c}$ Determined by HPLC on chiral stationary phase after identification of the enantiomers by baseline separation on the racemic mixture.

(ii) In the literature, catalysts I and II scarcely allow the reaching of high enantiomeric excesses, and bulkier congeners such as III are often preferred. ${ }^{14}$

(iii) An enantiomeric excess determination for product $\mathbf{4 b}$ ( $98 \%$ ee) was performed by HPLC on chiral stationary phase using an Astec Chirobiotic V2 column (Figure 2a). ${ }^{10 a}$ However, no chromatogram of the racemic mixture was provided to ascertain the identification of the two enantiomers but only the chromatogram of the "racemic mixture spiked with product from reaction with catalyst", which shows no baseline separation between the enantiomers in the HPLC conditions employed. Moreover, the former chromatogram disappeared from the Supporting Information in a correction of the original article that was published in $2014 .^{15}$

(iv) For all other products, experimental proof for the identification of the two enantiomers (that is to say, the HPLC chromatogram of the racemic mixture with baseline separation) was not provided. Sometimes, the retention time for the minor enantiomer was even missing. ${ }^{10 a}$ The correction added chromatograms of coelution of the racemic mixture and the supposedly enantioenriched product for six compounds of the reaction scope. ${ }^{15}$ However, there was once again no baseline separation. Individual elution conditions were not given and were likely to be different from the ones used for the determination of the enantiomeric excesses since retention times were utterly different (shift up to 14 $\min ) .^{12}$

Intrigued by these observations, we embarked on an in-depth evaluation of the results presented in the original report leading to $\mathbf{4 b}$ with the model substrates shown in Figure 1. At first, product formation over time was monitored by ${ }^{1} \mathrm{H}$ NMR. In the presence of catalyst $\mathbf{I}$, product started to appear after half an hour of reaction. This induction period is probably necessary to attain concentrations of the intermediates of the multicomponent reaction that are high enough to allow the formation of the target polyhydroquinoline $4 \mathrm{~b}$. More interestingly, the curve of product formation over time seems to present an inflection point around $3 \mathrm{~h}$, when the reaction actually accelerates. When catalyst I was omitted, the exact same curve was obtained with just a slightly extended induction period.
It should be noted that, during the reaction, three molecules of water and one of acetic acid are expelled. We surmised that the increasing concentration of the latter one might explain the rate acceleration in a scenario where both acidic species present in the reaction mixture (catalyst $\mathrm{I}$ and $\mathrm{AcOH}$ ) actually promote product formation. Complementary to that, no conversion of the three organic substrates was observed when no $\mathrm{NH}_{4} \mathrm{OAc}$ was present in the reaction mixture (Table 1 , entry 1 ), even in the presence of $\mathrm{AcOH}$ (entry 2), highlighting that the nitrogen source is required early in the reaction mechanism, presumably in initial enamine and/or iminium ion formation. ${ }^{16}$ The replacement of $\mathrm{NH}_{4} \mathrm{OAc}$ by other ammonia sources $\left(\mathrm{NH}_{4} \mathrm{Cl}\right.$, $\mathrm{NH}_{4} \mathrm{HCO}_{3}, \mathrm{NH}_{3}$ in $\mathrm{MeOH}$, or aqueous $\mathrm{NH}_{3}$ ) or surrogates (HMDS) was also unsuccessful, providing either no product or the racemic product. ${ }^{12}$ Replacing catalyst I by II also present in the original report from the group of Gestwicki or the popular TRIP catalyst III ${ }^{17}$ (entries 3 and 4) led to no improvement. Finally, reducing the reaction temperature does not appear as a solution to solve the enantioselectivity issue either (entries 5 and 6).

We also conducted a thorough HPLC study on racemic compound $\mathbf{4 b}$ (Figure 2). When trying to reproduce the elution conditions of the original report (Figure $2 \mathrm{a}$ ), ${ }^{10 a}$ no separation of the enantiomers was observed (Figure $2 \mathrm{~b}$ ).${ }^{18}$ On the opposite side, baseline separation was achieved with several other chiral columns including Chiralpak IC (Figure 2c). ${ }^{12}$ Moreover, a sample of enantiopure polyhydroquinoline $4 \mathrm{~b}$ (enantiomer eluted second in the HPLC conditions presented in Figure 2c) was obtained via semipreparative HPLC. Its specific optical rotation $\left(\mathrm{CHCl}_{3}, \lambda=589 \mathrm{~nm}, c=25 \mathrm{mg} \mathrm{mL}^{-1}, 25^{\circ} \mathrm{C}\right)$ is -105 , to be compared with the +16 value given in the literature in the same conditions. ${ }^{10 a}$ The strong deviation between absolute values of the optical rotations is an additional indication that the product from the original report was probably not enantiopure 4b.

To finish our study, we evaluated the behavior of several other aldehydes presented in the initial report on the enantioselective synthesis of polyhydroquinolines $\mathbf{4 c - 4 f}$ (Table 2). ${ }^{10 a}$ In line with the observation on the standard substrate, no enantioinduction was observed for both products $\mathbf{4 c}$ and $\mathbf{4 d}$, obtained from an electron-rich aldehyde and an electron-poor one, respectively (entries 1 and 2). In a similar fashion, 4-alkyl- 
substituted polyhydroquinolines $4 \mathbf{e}$ was also formed as a racemic product (entry 3 ). Recently, Natale and co-workers applied the title method to a few oxazole-4-carbaldehydes using TRIP catalyst III. ${ }^{19}$ Once again, HPLC traces presented in this publication are not fully convincing since there are discrepancies between retention times on chromatograms of the racemic product and the one obtained with the chiral phosphoric acid catalyst. ${ }^{12}$ Moreover, the authors claim enantiomeric excesses higher than $90 \%$, but without giving precise values. When trying to reproduce these results, we observed the formation of the expected product $4 \mathrm{f}$ in moderate yield and with marginal enantioselectivity ( $7 \%$ ee, entry 4$)$.

As a summary, a careful survey on the multicomponent phosphoric-acid-catalyzed synthesis of polyhydroquinolines ${ }^{10}$ was conducted. Contrary to the initial report, our study shed a new light on this transformation, where the organocatalyst actually seems to have no decisive influence either on the reaction rate or on the enantiodetermining step. As a more general conclusion, the present study along with similar ones ${ }^{20}$ should be seen as a reminder for both authors working in enantioselective catalysis and reviewers that very careful attention should be placed on the evaluation of the solidity of experimental evidence proposed to determine enantiomeric excess values.

\section{AUTHOR INFORMATION}

\section{Corresponding Authors}

Cyril Bressy - Aix Marseille Univ, CNRS, Centrale Marseille, iSm2, Marseille 13397, France; 으잉.org/0000-00032944-8274; Email: cyril.bressy@univ-amu.fr

Xavier Bugaut - Aix Marseille Univ, CNRS, Centrale Marseille, iSm2, Marseille 13397, France; 10 orcid.org/0000-00028424-0129; Email: xavier.bugaut@univ-amu.fr

Jean Rodriguez - Aix Marseille Univ, CNRS, Centrale Marseille, iSm2, Marseille 13397, France;

Email: jean.rodriguez@univ-amu.fr

\section{Authors}

Ophélie Quinonero - Aix Marseille Univ, CNRS, Centrale Marseille, iSm2, Marseille 13397, France

Clément Lemaitre - Aix Marseille Univ, CNRS, Centrale Marseille, iSm2, Marseille 13397, France

Marion Jean - Aix Marseille Univ, CNRS, Centrale Marseille, iSm2, Marseille 13397, France; ㅇo orcid.org/0000-00030524-8825

Nicolas Vanthuyne - Aix Marseille Univ, CNRS, Centrale Marseille, iSm2, Marseille 13397, France; $\odot$ orcid.org/00000003-2598-7940

Christian Roussel - Aix Marseille Univ, CNRS, Centrale Marseille, iSm2, Marseille 13397, France

Damien Bonne - Aix Marseille Univ, CNRS, Centrale Marseille, iSm2, Marseille 13397, France; $\odot$ orcid.org/00000003-4479-4626
Thierry Constantieux - Aix Marseille Univ, CNRS, Centrale Marseille, iSm2, Marseille 13397, France

Notes

The authors declare no competing financial interest.

\section{ACKNOWLEDGMENTS}

We warmly thank Roselyne Rosas (Aix Marseille Univ, CNRS, Centrale Marseille, FSCM, Spectropole, Marseille, France) for ${ }^{1}$ H NMR kinetic experiments, the whole team of the Spectropole for analytical work (www.spectropole.fr), and Lucie Fournier (Aix Marseille Univ, CNRS, Centrale Marseille, iSm2, Marseille, France) for the preparation of substrates and precursors of catalysts. Financial support from Aix Marseille Université, Centrale Marseille, the CNRS, and the Agence Nationale de la Recherche (ANR-13-BS07-0005, PhD scholarship for O.Q.) is acknowledged. Moreover, the project leading to this publication has received funding from Excellence Initiative of Aix-Marseille University-A*MIDEX, a French "Investissements d'Avenir" programme (scholarship for C.L.).

\section{REFERENCES}

(1) (a) Quinonero, O.; Jean, M.; Vanthuyne, N.; Roussel, C.; Bonne, D.; Constantieux, T.; Bressy, C.; Bugaut, X.; Rodriguez, J. Angew. Chem., Int. Ed. 2016, 55, 1401-1405. For the use of this strategy to prepare 3-arylfuran atropisomers, see: (b) Raut, V. S.; Jean, M.; Vanthuyne, N.; Roussel, C.; Constantieux, T.; Bressy, C.; Bugaut, X.; Bonne, D.; Rodriguez, J. J. Am. Chem. Soc. 2017, 139, 2140.

(2) (a) Hantzsch, A. Ber. Dtsch. Chem. Ges. 1881, 14, 1637. (b) Vanden Eynde, J.; Mayence, A. Molecules 2003, 8, 381. (c) Xia, J.-J.; Wang, G.-W. Synthesis 2005, 2379. (d) Liéby-Muller, F.; Allais, C.; Constantieux, T.; Rodriguez, J. Chem. Commun. 2008, 4207. (e) Allais, C.; Grassot, J.-M.; Rodriguez, J.; Constantieux, T. Chem. Rev. 2014, $114,10829$.

(3) For reviews on the organocatalytic synthesis of DHPs, see: (a) Thu Pham, H.; Chataigner, I.; Renaud, J.-L. Curr. Org. Chem. 2012, 16, 1754. (b) Wan, J.-P.; Liu, Y. RSC Adv. 2012, 2, 9763. (c) Bugaut, X.; Bonne, D.; Coquerel, Y.; Rodriguez, J.; Constantieux, T. Curr. Org. Chem. 2013, 17, 1920. (d) Auria-Luna, F.; Marqués-López, E.; Herrera, R. P. Adv. Synth. Catal. 2017, 359, 2161.

(4) (a) Berson, J. A.; Brown, E. J. Am. Chem. Soc. 1955, 77, 450. (b) Meyers, A. I.; Wettlaufer, D. G. J. Am. Chem. Soc. 1984, 106, 1135. (c) Wolf, C. In Dynamic Stereochemistry of Chiral Compounds: Principles and Applications; RSC: Cambridge, 2008; pp 233-271. (d) Quinonero, O.; Bressy, C.; Bugaut, X. Angew. Chem., Int. Ed. 2014, 53, 10861. (e) Pantaine, L.; Moreau, X.; Coeffard, V.; Greck, C. Tetrahedron Lett. 2016, 57, 2567. (f) Nguyen, T. T. Org. Biomol. Chem. 2019, 17, 6952.

(g) Yang, H.; Chen, J.; Zhou, L. Chem. - Asian J. 2020, 15, 2939.

(5) Bringmann, G.; Price Mortimer, A. J.; Keller, P. A.; Gresser, M. J.; Garner, J.; Breuning, M. Angew. Chem., Int. Ed. 2005, 44, 5384.

(6) Molleti, N.; Allu, S.; Ray, S. K.; Singh, V. K. Tetrahedron Lett. 2013, $54,3241$.

(7) Moreau, J.; Duboc, A.; Hubert, C.; Hurvois, J.-P.; Renaud, J.-L. Tetrahedron Lett. 2007, 48, 8647.

(8) Jiang, J.; Yu, J.; Sun, X.-X.; Rao, Q.-Q.; Gong, L.-Z. Angew. Chem., Int. Ed. 2008, 47, 2458

(9) Rueping, M.; Sugiono, E.; Merino, E. Chem. - Eur. J. 2008, 14, 6329.

(10) (a) Evans, C. G.; Gestwicki, J. E. Org. Lett. 2009, 11, 2957.

(b) Evans, C. G.; Jinwal, U. K.; Makley, L. N.; Dickey, C. A.; Gestwicki, J. E. Chem. Commun. 2011, 47, 529.

(11) The partial salification of catalyst during chromatography can sometimes account for discrepancies in the reactivity and selectivity: 
Klussmann, M.; Ratjen, L.; Hoffmann, S.; Wakchaure, V.; Goddard, R.; List, B. Synlett 2010, 2189.

(12) See the Supporting Information for more details.

(13) Uraguchi, D.; Terada, M. J. Am. Chem. Soc. 2004, 126, 5356.

(14) In the middle of dozens of reactions with lower ee values with catalyst I, scattered examples reaching higher than $90 \%$ ee exist. See for example: (a) Dumoulin, A.; Bernadat, G.; Masson, G. J. Org. Chem. 2017, 82, 1775. The best ee value ever reported for catalyst II is $35 \%$ : (b) Neel, A. J.; Milo, A.; Sigman, M. S.; Toste, F. D. J. Am. Chem. Soc 2016, 138, 3863. Virtually enantiopure compounds have been obtained when chiral catalyst $\mathbf{I}$ is used in combination with another chiral enantiopure catalyst. See for example: (c) Han, Y.; Zheng, B.; Peng, Y. Adv. Synth. Catal. 2015, 357, 1136.

(15) Evans, C. G.; Gestwicki, J. E. Org. Lett. 2014, 16, 6040.

(16) The precise mechanism of the reaction remains unclear as no conversion was observed between enamines and Knoevenagel adducts obtained when combining pairs of the four starting materials. See the Supporting Information for further details and see also: Chung, T.-W.; Narhe, B. D.; Lin, C.-C.; Sun, C.-M. Org. Lett. 2015, 17, 5368.

(17) (a) Hoffmann, S.; Seayad, A. M.; List, B. Angew. Chem., Int. Ed. 2005, 44, 7424. (b) Parmar, D.; Sugiono, E.; Raja, S.; Rueping, M. Chem. Rev. 2014, 114, 9047. (c) Tiago Menezes Correia, J. Synlett 2015 26, 416.

(18) Elution conditions cannot be strictly identical, as some parameters (ageing of the column, e.g.) cannot be reproduced.

(19) Steiger, S. A.; Li, C.; Campana, C. F.; Natale, N. R. Tetrahedron Lett. 2016, 57, 423.

(20) Denmark, S. E.; Carson, N. Org. Lett. 2015, 17, 5728. 